\title{
Food choices to meet nutrient recommendations for the adult Brazilian population based on the linear programming approach
}

\author{
Quenia dos Santos ${ }^{1,2, *}$, Rosely Sichieri ${ }^{1}$, Nicole Darmon ${ }^{3}$, Matthieu Maillot ${ }^{4}$ and \\ Eliseu Verly-Junior ${ }^{1}$ \\ 'Institute of Social Medicine, State University of Rio de Janeiro, Rio de Janeiro, RJ, Brazil: ${ }^{2}$ Food Design and \\ Consumer Behaviour Section, Department of Food Science, University of Copenhagen, Rolighedsvej 26, 1958 \\ Frederiksberg C, Denmark: ${ }^{3}$ Markets, Organizations, Institutions and Stakeholders Strategies, Institut National de la \\ Recherche Agronomique (INRA), Montpellier, France: ${ }^{4}$ MS-Nutrition, Marseille, France
}

Submitted 6 June 2017: Final revision received 31 October 2017: Accepted 27 November 2017: First published online 18 January 2018

\begin{abstract}
Objective: To identify optimal food choices that meet nutritional recommendations to reduce prevalence of inadequate nutrient intakes.

Design: Linear programming was used to obtain an optimized diet with sixty-eight foods with the least difference from the observed population mean dietary intake while meeting a set of nutritional goals that included reduction in the prevalence of inadequate nutrient intakes to $\leq 20 \%$.

Setting: Brazil.

Subjects: Participants (men and women, $n$ 25324) aged 20 years or more from the first National Dietary Survey (NDS) 2008-2009.

Results: Feasible solution to the model was not found when all constraints were imposed; infeasible nutrients were $\mathrm{Ca}$, vitamins $\mathrm{D}$ and $\mathrm{E}, \mathrm{Mg}, \mathrm{Zn}$, fibre, linolenic acid, monounsaturated fat and $\mathrm{Na}$. Feasible solution was obtained after relaxing the nutritional constraints for these limiting nutrients by including a deviation variable in the model. Estimated prevalence of nutrient inadequacy was reduced by $60-70 \%$ for most nutrients, and mean saturated and trans-fat decreased in the optimized diet meeting the model constraints. Optimized diet was characterized by increases especially in fruits $(+92 \mathrm{~g})$, beans $(+64 \mathrm{~g})$, vegetables $(+43 \mathrm{~g})$, milk $(+12 \mathrm{~g})$, fish and seafood $(+15 \mathrm{~g})$ and whole cereals $(+14 \mathrm{~g})$, and reductions of sugar-sweetened beverages $(-90 \mathrm{~g})$, rice $(-63 \mathrm{~g})$, snacks $(-14 \mathrm{~g})$, red meat $(-13 \mathrm{~g})$ and processed meat $(-9 \cdot 7 \mathrm{~g})$.

Conclusion: Linear programming is a unique tool to identify which changes in the current diet can increase nutrient intake and place the population at lower risk of nutrient inadequacy. Reaching nutritional adequacy for all nutrients would require major dietary changes in the Brazilian diet.
\end{abstract}

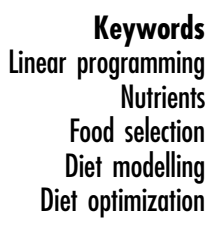

Prevalence of inadequate nutrient intake is high in many parts of the world ${ }^{(1,2)}$, including Brazil. According to the last Brazilian National Dietary Survey (2008/2009), the prevalence of inadequate nutrient intake is greater than $70 \%$ for $\mathrm{Ca}$, vitamins $\mathrm{D}$ and $\mathrm{E}, \mathrm{Mg}$ and vitamin $\mathrm{A}$ in the adult and elderly population ${ }^{(3,4)}$. Diet optimization methods can be used as a tool for achieving nutrient goals while planning feasible diets based on local and culturally specific foods for either a population or individuals ${ }^{(5-7)}$. Diet optimization is based on linear programming, which is a mathematical method that optimizes (minimizes or maximizes) a defined function (e.g. the least cost; the least difference between optimized and observed diets) while respecting multiple constraints, such as a set of nutrient recommendations. This method has been used in previous studies to formulate dietary patterns in accordance with nutrient-based recommendations ${ }^{(8,9)}$ and to assess the impact of $\operatorname{cost}^{(10,11)}$ and environmental constraints ${ }^{(12)}$ on nutritionally adequate food choices.

Studies conducted using diet optimization in Europe, the USA and Asia, among others, have identified the main dietary modifications needed to fulfil nutrient recommendations in the range of acceptable consumption constraints, at the population level ${ }^{(8,13,14)}$. However, applying results from these countries is difficult because food intake in Brazil has peculiarities, such as consumption of rice, 
beans and beef almost every day, and low consumption of fruits, vegetables, fish and dairy products. The aim of the present study was to identify the smallest modifications from the current food intake that could reach the target prevalence of $20 \%$ or less of inadequate intake for each nutrient.

\section{Methods}

\section{Study population}

Dietary data from the first National Dietary Survey (NDS) were used. NDS was conducted along with the Household Budget Survey (HBS) 2008-2009 carried out by the Brazilian Institute of Geography and Statistics ${ }^{(15)}$. HBS used a two-stage sampling: the first randomly selected census tracts and the second proceeded with random selection of the households. The 12800 sectors of the set of census tracts were grouped into 550 household strata with geographical and socio-economic homogeneity. The number of tracts randomly selected from each stratum was proportional to the number of households in this stratum. Households in each stratum were uniformly distributed throughout 12-month periods to accommodate seasonal variation in food intake.

Dietary intake was collected from two non-consecutive food records of adults and elderly people ( $n$ 25324; aged 20 years or more, excluding pregnant and lactating women), in which the individual recorded all foods and beverages consumed, including the time of intake, quantities consumed in portion sizes and preparation form. Details on sampling data collection are available elsewhere $^{(16)}$. A list of 305 foods were reported in the survey (many of them already grouped into subgroups; e.g. different types of breads into breads). From this list, we excluded non-food nutrient and energy sources such as coffee and tea (without sugar) and alcoholic beverages. To have a better interpretability and simplicity of the models, we considered only foods that together accounted for at least $95 \%$ of the total energy and nutrient intakes (considering all nutrients used in this analysis), resulting in a final list of sixty-eight foods or food groups (called 'food items'). Food contribution to total energy and nutrient intakes was calculated as food item energy or nutrient content divided by total energy or nutrient content from all foods. Mean population food intakes were calculated considering sampling weights for these sixty-eight food items and are referred to herein as 'mean observed diet'.

\section{Description of optimized models using linear programming}

Linear programming for modelling diets was described previously elsewhere ${ }^{(17)}$. An optimization model is defined by an objective function dependent on many variables (i.e. decision variables) restricted by various constraints. Decision variables are the quantities for the sixty-eight food variables that will be modelled to satisfy all the nutritional and acceptability constraints. In the present study, the diet optimization model was used to design a diet that provides nutrients meeting nutritional goals while departing as least as possible from the current observed mean diet. In other words, the quantities of foods in the optimized diet should be as close as possible to the mean observed food intakes. The objective function can also minimize undesirable deviations from nutrient goals (an undesirable deviation is the difference between the target and the optimized content for a nutrient) ${ }^{(9)}$ which are not achievable. For example, an undesirable negative deviation of $50 \mathrm{mg}$ occurs when the content for a given nutrient in the optimized diet is $250 \mathrm{mg}$ instead of a target of $300 \mathrm{mg}$. The deviance for a nutrient expresses the least optimized difference between the target and the solution when the constraint cannot be met. Standardized deviation factors, (desired-actual)/desired, can be included in the model for all nutrients simultaneously. The following function was created:

$$
Y=i=1 i=g\left(\frac{Q_{i}^{o p t}-Q_{i}^{o b s}}{Q_{i}^{o b s}}\right)+\sum_{n=1}^{n=N} d_{n}
$$

where $Y$ is the objective function to be minimized, $g$ is the total number of food items, $Q_{i}^{o p t}$ is the quantity (in grams) of food item $i$ in the optimized diet and $Q_{i}^{o b s}$ is the mean quantity of the same item $i$ in the observed diet; $d_{n}$ is the standardized deviation factor for nutrients $n$ ( $N$ is the total of infeasible nutrients). This is a non-linear function due to the use of absolute function, which was linearized including a set of linear constraints following a similar procedure to that described in detail elsewhere ${ }^{(18)}$. All linear programming models were run with the Optmodel Procedure of the statistical software package SAS version 9.4 .

\section{Input data for the model}

\section{Food composition database}

The food composition data set specially compiled for Brazilian nutritional surveys ${ }^{(19)}$ was used. When individual foods were grouped into a single food item (e.g. different types of rice), the nutrient composition of the food item was the mean composition of the foods weighted by the frequency of reporting of each item that composes the group. All food items were categorized into six food groups (fruits, vegetables, seeds and legumes; cereals; dairy; cereals; meat; oils; others) and twenty-six food subgroups. Food classification was based on previous studies on household food availability in Brazil ${ }^{(20,21)}$, but collapsing foods with low frequency of intake such as manioc into the subgroup tubers. In addition, milk was split into whole milk and non-fat milk because of the saturated fat content; and leafy vegetables were classified as a separate group because they usually weigh much less 
compared with other vegetables, thus they are expected to be consumed in lower quantities.

\section{Acceptability constraints}

This term refers to boundaries in which the optimized diet can deviate from the observed mean intake. These limitations help avoid a diet that is culturally or socially unacceptable. Boundaries were based on $2 \mathrm{~d}$ mean intakes of each food item per stratum; this procedure removes, at least in part, the within-person variance in dietary intake presented when dietary information is provided from one or few collection days, and approaches the mean usual intake in the stratum ${ }^{(22)}$. Then, the 10th and 70th percentiles from the distribution of mean intakes were estimated and arbitrarily set as the lower and upper acceptability constraints, respectively (Table 1).

\section{Nutritional constraints}

This term refers to nutritional goals that the optimized diet should meet. We focused on nutrients with a high prevalence of inadequate intake observed in Brazil ${ }^{(3)}$. However, a wider set of nutrients was also included to prevent the optimized diet from being an unbalanced diet (e.g. to achieve Ca requirement an increase in saturated fat might be necessary, hence there was a need to impose

Table 1 Acceptability constraints on food content imposed in the linear programming model

\begin{tabular}{|c|c|c|}
\hline $\begin{array}{l}\text { Foods (groups and } \\
\text { subgroups) }(\mathrm{g} / \mathrm{d})\end{array}$ & $\begin{array}{l}\text { Lower 10th } \\
\text { percentile }\end{array}$ & $\begin{array}{l}\text { Upper 70th } \\
\text { percentile }\end{array}$ \\
\hline \multicolumn{3}{|c|}{ Fruits, vegetables, seeds and legumes } \\
\hline Nuts & 0.1 & 0.9 \\
\hline Leafy vegetables & 2.5 & $24 \cdot 1$ \\
\hline Tubers & 5.5 & 39.9 \\
\hline Other vegetables & $5 \cdot 6$ & $45 \cdot 2$ \\
\hline Beans & 79.0 & 248.2 \\
\hline Fruits & $37 \cdot 0$ & 223.9 \\
\hline \multicolumn{3}{|l|}{ Cereals } \\
\hline Rice & $80 \cdot 6$ & 194.3 \\
\hline Breads & 18.9 & $69 \cdot 2$ \\
\hline Cake, cookies & $7 \cdot 2$ & 31.9 \\
\hline Pasta & $14 \cdot 1$ & 61.5 \\
\hline Whole cereals & 1.7 & 23.2 \\
\hline \multicolumn{3}{|l|}{ Dairy } \\
\hline Cheese & $1 \cdot 2$ & $11 \cdot 2$ \\
\hline Yoghurt & $2 \cdot 1$ & $14 \cdot 2$ \\
\hline Non-fat milk & 1.2 & $10 \cdot 0$ \\
\hline Whole milk & $46 \cdot 6$ & $109 \cdot 4$ \\
\hline \multicolumn{3}{|l|}{ Meat } \\
\hline Processed meat & 1.6 & 11.9 \\
\hline Eggs & 4.0 & $15 \cdot 9$ \\
\hline Chicken & $17 \cdot 2$ & $49 \cdot 0$ \\
\hline Fish, seafood & 4.7 & $47 \cdot 6$ \\
\hline Red meat & $32 \cdot 3$ & $106 \cdot 8$ \\
\hline \multicolumn{3}{|l|}{ Oils } \\
\hline Margarine, butter & $2 \cdot 0$ & $9 \cdot 2$ \\
\hline Olive & 0.0 & $0 \cdot 1$ \\
\hline \multicolumn{3}{|l|}{ Others } \\
\hline $\begin{array}{l}\text { Sugar-sweetened } \\
\text { beverages }\end{array}$ & 31.9 & $132 \cdot 0$ \\
\hline Snacks & 1.7 & $16 \cdot 2$ \\
\hline Manioc flour & 0.6 & $9 \cdot 6$ \\
\hline Sweets & $3 \cdot 8$ & 20.9 \\
\hline
\end{tabular}

constraints on saturated fat as well). For micronutrients such as $\mathrm{Ca}, \mathrm{Mg}, \mathrm{Fe}, \mathrm{P}, \mathrm{Cu}, \mathrm{Zn}$, vitamins $\mathrm{A}, \mathrm{B}_{6}, \mathrm{~B}_{12}, \mathrm{C}, \mathrm{D}$ and $\mathrm{E}$, thiamin, riboflavin, niacin and folate, the cut-offs were derived from the Estimated Average Requirement $(\mathrm{EAR})^{(23-25)}$, targeting a prevalence of inadequate nutrient intake of $20 \%$ or less. The EAR are the average daily nutrient intake levels estimated to meet the requirement of half the healthy individuals in a life stage and gender group $^{(26)}$. Thus, if the population mean intake of a nutrient is at EAR level, under assumption of a normal distribution of intake, it means that $50 \%$ of the population will be inadequate regarding their nutrient requirement ${ }^{(27)}$. To reach the target of $\leq 20 \%$ prevalence of inadequate nutrient intake, a set of constraints considering both EAR and current usual nutrient intake were developed. First, we estimated the distribution of usual nutrient intakes by agesex group by removing within-person variance using proper methodology ${ }^{(28)}$. The nutritional constraint (i.e. the lowest acceptable intake) for a given nutrient for each age-sex group was calculated as follows:

$$
\text { Constraint }=\operatorname{Mean}_{(\text {age }- \text { sex })}-\mathrm{P}_{20(\text { age }- \text { sex })}+\mathrm{EAR}_{(\text {age }- \text { sex })},
$$

where the parameters are mean observed nutrient intake, 20th percentile of the usual nutrient intake and EAR for the nutrient. Finally, we calculated the overall mean constraints weighted by the frequency of age and sex subgroups in the population. Prevalence of inadequacy was calculated as the proportion of people with usual intake below the EAR assuming the same between-person variability in nutrient intake for both observed and optimized diets. For micronutrients with no EAR (K, Mn, vitamin $\mathrm{K}$ and pantothenic acid), we constrained the intake as equal to or higher than the observed mean intake. For $\mathrm{Na}$, we considered only the intrinsic content in foods because there is no information on how accurate is the estimate of added salt in food preparations. The $\mathrm{Na}$ constraint was a $58 \%$ reduction in mean observed $\mathrm{Na}$ intake as targeted by the Brazilian Ministry of Health as part of policies to reduce the salt in processed foods ${ }^{(29)}$. Red and processed meat was constrained to $500 \mathrm{~g} /$ week $^{(30)}$. Total energy content was not constrained since there is no precise measure of the energy under-reporting in our population. Models were allowed to determine the amount of energy required to meet nutrient recommendations in accordance with the imposed food and nutrient constraints. Nutritional constraints for macro- and micronutrients, and the references used, are provided in Table 2 .

\section{Results}

Mean age for this sample was 43 (SD 27.0) years; $47 \%$ were male; $35 \%$ were overweight and 16\% were obese. High school and college were reported by $39 \%$ of the population; $46 \%$ had monthly family income $<1$ minimum wage 
Table 2 Macro- and micronutrient constraints imposed in the linear programming model

\begin{tabular}{|c|c|c|}
\hline Nutrient & Units & Constraint \\
\hline \multicolumn{3}{|l|}{ Macronutrients } \\
\hline Total carbohydrates & $\% \mathrm{E}$ & $45-55 \ddagger$ \\
\hline Free sugars & $\% \mathrm{E}$ & $\leq 10 \S$ \\
\hline Total fibre & $\mathrm{g}$ & $\geq 31 \ddagger$ \\
\hline Protein & $\% \mathrm{E}$ & $\geq 10 \ddagger$ \\
\hline Total fat & $\% \mathrm{E}$ & $25-35 \ddagger$ \\
\hline Linoleic acid & $\% \bar{E}$ & $\geq 5 \S$ \\
\hline Linolenic acid & $\% \mathrm{E}$ & $\geq 1 \S$ \\
\hline Saturated fat & $\% \mathrm{E}$ & $\leq 10 \S$ \\
\hline Trans-fat & $\% \mathrm{E}$ & $\leq 1 \ddagger$ \\
\hline Polyunsaturated fat & $\% \mathrm{E}$ & $\geq 6 \S$ \\
\hline Monounsaturated fat & $\% \mathrm{E}$ & $\geq \overline{10} \|$ \\
\hline \multicolumn{3}{|l|}{ Micronutrients } \\
\hline $\mathrm{Na}$ & $\mathrm{mg}$ & $\leq 734 \uparrow$ \\
\hline $\mathrm{Ca}$ & $\mathrm{mg}$ & $\geq 1021^{\star \star}$ \\
\hline $\mathrm{Cu}$ & $\mathrm{mg}$ & $\geq 1 \cdot 1^{\star *}$ \\
\hline $\mathrm{Fe}$ & $\mathrm{mg}$ & $\geq \overline{1} 0 \cdot 7^{\star *}$ \\
\hline$P$ & $\mathrm{mg}$ & $\geq 888^{\star \star}$ \\
\hline $\mathrm{Mg}$ & $\mathrm{mg}$ & $\geq 377^{\star \star}$ \\
\hline $\mathrm{Zn}$ & $\mathrm{mg}$ & $\geq 11 \cdot 7^{\star \star}$ \\
\hline $\mathrm{Mn}$ & $\mathrm{mg}$ & $\geq 2 \cdot 4 \|$ \\
\hline $\mathrm{K}$ & $\mathrm{mg}$ & $\geq 19 \overline{4} 6 \|^{\prime \prime}$ \\
\hline Niacin & $\mathrm{mg}$ & $\geq 16 \cdot 4^{\star \star}$ \\
\hline Vitamin A & $\mu g^{*}$ & $\geq \overline{8} 03^{\star \star}$ \\
\hline Thiamin & $\mathrm{mg}$ & $\geq 1 \cdot 3^{\star \star}$ \\
\hline Riboflavin & $\mathrm{mg}$ & $\geq 1 \cdot 5^{\star \star}$ \\
\hline Vitamin $\mathrm{B}_{6}$ & $\mathrm{mg}$ & $\geq 1 \cdot 6^{\star *}$ \\
\hline Vitamin $B_{12}$ & $\mathrm{mg}$ & $\geq 4 \cdot 2^{\star \star}$ \\
\hline Vitamin C & $\mathrm{mg}$ & $\geq 173^{\star \star}$ \\
\hline Vitamin D & $\mu \mathrm{g}$ & $\geq 10^{\star \star}$ \\
\hline Vitamin E & $\mathrm{mg}$ & $\geq 12^{\star \star}$ \\
\hline Folate & $\mu \mathrm{g} \dagger$ & $\geq \overline{4} 26^{\star \star}$ \\
\hline Pantothenic acid & $\mathrm{mg}$ & $\geq 2.4 \|$ \\
\hline Vitamin $\mathrm{K}$ & $\mathrm{mg}$ & $\geq \overline{8} 9 \cdot 3$ \\
\hline
\end{tabular}

$\% \mathrm{E}$, percentage of energy.

*Micrograms of retinol activity equivalents.

†Micrograms of dietary folate equivalents.

łInstitute of Medicine ${ }^{(25)}$.

§World Health Organization ${ }^{(39)}$

\|Observed intake.

ICOnsidering a $58 \%$ reduction in salt intake from the Brazilian plan to reduce salt in processed foods ${ }^{(29)}$.

${ }^{\star *}$ Derived from the Estimated Average Requirement ${ }^{(23-25)}$.

and $14 \%>3$ minimum wages ( 1 minimum wage $=$ \$US 180 or 430 Brazilian Reals; reference period was 15 January 2009).

It was not possible to find a feasible solution when all constraints were imposed on the model; infeasible nutrients were $\mathrm{Ca}$, vitamins $\mathrm{D}$ and $\mathrm{E}, \mathrm{Mg}, \mathrm{Zn}$, fibre, linolenic acid, monounsaturated fat and $\mathrm{Na}$. A feasible solution was obtained after relaxing the nutritional constraints for these limiting nutrients by including a deviation variable in the model, and the results for the optimized diet refer to this model. Observed and optimized mean nutrient contents and estimated prevalence of nutrient inadequacy are shown in Table 3. The maximum achievable contents for the limiting nutrient were $513 \mathrm{mg}$ (Ca), $263 \mathrm{mg}(\mathrm{Mg}$ ), $10.2 \mathrm{mg}(\mathrm{Zn}), 3.3 \mu \mathrm{g}$ (vitamin D), $5.6 \mathrm{mg}$ (vitamin E), $1.4 \mathrm{~g}$ (linolenic acid), $16.8 \mathrm{~g}$ (monounsaturated fat) and $23.2 \mathrm{~g}$ (fibre), and the minimum for $\mathrm{Na}$ was $1143.3 \mathrm{mg}(13 \%$ reduction from the mean observed intake). The remaining nutritional constraints were fully satisfied. Estimated prevalence of nutrient inadequacy was reduced by $60-70 \%$ for $\mathrm{P}$, niacin, vitamin $\mathrm{A}$, thiamin, riboflavin, vitamin $\mathrm{B}_{6}$, vitamin $\mathrm{C}$ and folate. Modest reductions of estimated prevalence of nutrient inadequacy were observed for $\mathrm{Mg}$ (24\%) and $\mathrm{Ca}(5 \%)$. Vitamins D and E kept the same high inadequacy (99\%). The optimized diet also increased the mean content of nutrients with no EAR by about $30 \%$. Percentages of energy from macronutrients were within the acceptable range in both the observed and optimized diets. Mean saturated fat and trans-fat were reduced in the optimized diet and fell within the adequate value. Total weight and energy were slightly higher in the optimized $v$. the observed diet (1247v. $1156 \mathrm{~g}$ and $6966 v .6816 \mathrm{~kJ}$ (1665 v. $1629 \mathrm{kcal})$, respectively).

The food group contents in the observed and optimized diets are presented in Table 4. The optimized diet was characterized by increases especially in fruits $(+92 \mathrm{~g})$, beans $(+64 \mathrm{~g})$, vegetables $(+43 \mathrm{~g})$, whole milk $(+12 \mathrm{~g})$, fish and seafood $(+15 \mathrm{~g})$ and whole cereals $(+14 \mathrm{~g})$. Within the groups, some individual food items required a higher increase to meet nutritional goals. Among the fruits, the most important changes occurred to açai (increased from 2.3 to $18.7 \mathrm{~g}$ ), acerola (from 5 to $14 \mathrm{~g}$ ) and orange (from 49 to $58 \mathrm{~g}$ ). All fruits increased at the upper acceptability constraint. Among the vegetables, increases in tomato and courgette of about $3.5 \mathrm{~g}$ each were highlighted. On the other hand, sugar-sweetened beverages had the highest reduction (about $-90 \mathrm{~g}$ ), followed by rice $(-63 \mathrm{~g})$, snacks $(-14 \mathrm{~g})$, red meat $(-13 \mathrm{~g})$ and processed meats $(-9 \cdot 7 \mathrm{~g})$.

\section{Discussion}

In the present study, we demonstrate that it is possible to increase nutrient intakes, thus lowering the prevalence of inadequacy to less than $20 \%$ for the majority of the nutrients evaluated, and still reach other nutritional goals such energy share of macronutrients including free sugars and fatty acids. Most foods in the optimized diet did not differ strongly from the observed diet (up to $20 \mathrm{~g}$ difference), except for beans and fruits (which increased) and rice and sugar-sweetened beverages (which decreased). Beans are one of the most frequently consumed foods ${ }^{(31)}$ with the highest mean population intake in Brazil ${ }^{(15)}$. Along with the fact of having substantial content of nutrients, beans are among the five most important sources for most nutrients (exceptions are vitamins $\mathrm{A}, \mathrm{B}_{12}$ and C). In addition, they are the main food source of fibre, $\mathrm{Ca}$, $\mathrm{Mg}, \mathrm{P}, \mathrm{Fe}, \mathrm{K}, \mathrm{Cu}$ and vitamin $\mathrm{E}$ in the Brazilian diet (results from the analysis of food energy and nutrient contributions as described in the 'Methods' section, data not shown). This explains why the optimized diet demanded a higher amount of beans.

Higher demands for fruits and vegetables to meet nutritional goals were also described in studies from the 
Table 3 Nutrient contents and estimated prevalence of inadequacy in the observed and optimized diets

\begin{tabular}{|c|c|c|c|c|c|c|}
\hline \multirow[b]{2}{*}{ Nutrient } & \multicolumn{4}{|c|}{ Mean content } & \multicolumn{2}{|c|}{ Inadequacy $(\%)^{*}$} \\
\hline & \multicolumn{2}{|c|}{ Observed } & \multicolumn{2}{|c|}{ Optimized } & Observed & Optimized \\
\hline \multirow{3}{*}{$\begin{array}{l}\text { Energy (kJ) } \\
\text { Energy (kcal) }\end{array}$} & \multirow{2}{*}{\multicolumn{2}{|c|}{$\begin{array}{l}6816 \\
1629\end{array}$}} & \multirow{2}{*}{\multicolumn{2}{|c|}{$\begin{array}{l}6966 \\
1665\end{array}$}} & \multirow{3}{*}{-} & \multirow{3}{*}{-} \\
\hline & & & & & & \\
\hline & $g$ & $\% \mathrm{E}$ & $g$ & $\% \mathrm{E}$ & & \\
\hline Carbohydrates & 207 & 50 & 224 & 51 & - & - \\
\hline Free sugars & 30 & $7 \cdot 0$ & 25 & $5 \cdot 7$ & - & - \\
\hline Total fibre & 17.9 & & 23.2 & & _ & - \\
\hline Protein & 75 & 18 & 81 & 20 & - & - \\
\hline Total fat & 55 & 30 & 52 & 29 & - & - \\
\hline Linoleic acid & 9.1 & 5.0 & 9.5 & 5.2 & - & - \\
\hline Linolenic acid & $1 \cdot 1$ & 0.6 & $1 \cdot 3$ & 0.6 & - & - \\
\hline Saturated fat & $19 \cdot 1$ & $10 \cdot 0$ & $17 \cdot 1$ & $9 \cdot 3$ & - & - \\
\hline Trans-fat & 2.5 & 0.1 & 1.3 & 0.8 & - & - \\
\hline Polyunsaturated fat & 11.5 & $6 \cdot 3$ & 11.5 & $6 \cdot 2$ & - & - \\
\hline Monounsaturated fat & 19.0 & $10 \cdot 0$ & $16 \cdot 8$ & $10 \cdot 0$ & - & - \\
\hline $\mathrm{Na}(\mathrm{mg})$ & \multicolumn{2}{|c|}{1266.4} & \multicolumn{2}{|c|}{1143.3} & - & - \\
\hline $\mathrm{Ca}(\mathrm{mg})$ & \multicolumn{2}{|c|}{403.5} & \multicolumn{2}{|c|}{513.1} & 93 & 86 \\
\hline $\mathrm{Cu}(\mathrm{mg})$ & \multicolumn{2}{|c|}{1.1} & \multicolumn{2}{|c|}{$1 \cdot 7$} & 30 & 3 \\
\hline $\mathrm{Fe}(\mathrm{mg})$ & \multicolumn{2}{|c|}{10.5} & \multicolumn{2}{|c|}{$12 \cdot 4$} & 21 & 6 \\
\hline$P(m q)$ & \multicolumn{2}{|c|}{$866 \cdot 1$} & \multicolumn{2}{|c|}{$1015 \cdot 5$} & 23 & 7 \\
\hline $\mathrm{Mg}(\mathrm{mg})$ & \multicolumn{2}{|c|}{206.0} & \multicolumn{2}{|c|}{263.2} & 86 & 67 \\
\hline $\mathrm{Zn}(\mathrm{mq})$ & \multicolumn{2}{|c|}{10.2} & \multicolumn{2}{|c|}{$10 \cdot 2$} & 35 & 35 \\
\hline $\mathrm{Mn}(\mathrm{mg})$ & \multicolumn{2}{|c|}{2.4} & \multicolumn{2}{|c|}{2.6} & - & - \\
\hline $\mathrm{K}(\mathrm{mg})$ & \multicolumn{2}{|c|}{1951.3} & & & - & - \\
\hline Niacin (mg) & & & & & 60 & 20 \\
\hline Vitamin A (mg)† & & & & & 67 & 20 \\
\hline Thiamin $(\mathrm{mg})$ & & & & & 38 & 8 \\
\hline Riboflavin (mg) & & & & & 30 & 13 \\
\hline Vitamin $B_{6}(\mathrm{mg})$ & & & & & 26 & 9 \\
\hline Vitamin $\mathrm{B}_{12}(\mathrm{mg})$ & & & & & 10 & 1 \\
\hline Vitamin C (mg) & & & & & 56 & 1 \\
\hline Vitamin D (mq) & & & & & 99 & 99 \\
\hline Vitamin E (mg) & & & & & 99 & 99 \\
\hline Folate $(\mathrm{mq}) \pm$ & & & & & 31 & 8 \\
\hline Pantothenic acid (mg) & & & & & - & - \\
\hline Vitamin $\mathrm{K}(\mathrm{mg})$ & & & & & - & - \\
\hline
\end{tabular}

$\% \mathrm{E}$, percentage of energy.

Observed diet of Brazilian adults (men and women aged 20 years or more, $n 25324$ ) from the first National Dietary Survey 2008-2009. Optimized diet obtained by linear programming, using sixty-eight foods, to achieve the least difference from the observed population mean dietary intake while meeting a set of nutritional goals including a reduction in prevalence of inadequate nutrient intakes to $\leq 20 \%$.

${ }^{*}$ For nutrients with an Estimated Average Requirement established.

†Micrograms of retinol activity equivalents.

¥Micrograms of dietary folate equivalents.

$\mathrm{USA}^{(13)}$, France ${ }^{(10,11,14)}, \operatorname{Japan}^{(8)}$ and New Zealand ${ }^{(32)}$. On the other hand, sugar-sweetened beverages and rice were lower in the optimized diet, and this reduction was probably needed to accommodate higher quantities of macronutrients and fats from nutrient-dense foods included in the optimized diet. Similarly, reduction in red and processed meat was needed mainly due to the $\mathrm{Na}$ and saturated fat contents, being replaced in part by chicken and fish, which reflects the moderate inverse correlation of chicken and fish consumption with red meat observed in the population (data not shown).

For some nutrients, a solution could be reached only after relaxing their constraints. This resulted in the estimated prevalence of inadequacy for Ca and vitamins $\mathrm{D}$ and $\mathrm{E}$ remaining high and practically unaltered. To reach the initial target of less than or equal to $20 \%$ of inadequacy, the mean intake of some key foods should be allowed to exceed the upper limit of acceptability imposed. For example, one of the Ca-richest foods are dairy products ${ }^{(23)}$. Dairy's content in the optimized diet is at the upper limit of acceptability; a higher content would potentially be non-realistic or unaffordable. For example, an additional amount of $600 \mathrm{~g}$ in the mean intake of milk (the most important dairy product in Brazil) would be necessary to fulfil the Ca requirement, which certainly is a non-realistic amount (the 95th percentile for dairy intake is $212 \mathrm{~g}$ ). Regarding vitamins D and E, considering the richest foods, an additional amount of $210 \mathrm{~g}$ in the mean intake of fish, and $145 \mathrm{~g}$ in nuts, would overcome the inadequacy for those nutrients, respectively; however, both amounts are well above the highest intake observed in the population. The high inadequacy of vitamins $\mathrm{D}$ and $\mathrm{E}$, however, might not be of special concern due to the assumptions made in the recommendation intake definition. The established amount of intake of vitamin D needed to 
Table 4 Food contents in the observed and optimized diets

\begin{tabular}{|c|c|c|c|}
\hline Foods/food groups (g/d) & Observed & Optimized & Difference $^{*}$ \\
\hline \multicolumn{4}{|c|}{ Fruits, vegetables, seeds and legumes } \\
\hline Nuts & 0.2 & 1.23 & +1.03 \\
\hline Leafy vegetables & $11 \cdot 9$ & $23 \cdot 5$ & $+11 \cdot 6$ \\
\hline Tubers & $25 \cdot 8$ & 39.9 & $+14 \cdot 1$ \\
\hline Other vegetables & $27 \cdot 8$ & $45 \cdot 2$ & +17.5 \\
\hline Beans & 184.5 & $248 \cdot 2$ & $+63 \cdot 7$ \\
\hline Fruits & 131.9 & 223.8 & +91.9 \\
\hline \multicolumn{4}{|l|}{ Cereals } \\
\hline Rice & $157 \cdot 8$ & 94.7 & $-63 \cdot 1$ \\
\hline Breads & $63 \cdot 6$ & $66 \cdot 0$ & $+3 \cdot 1$ \\
\hline Cake, cookies & $25 \cdot 8$ & 31.9 & $+6 \cdot 1$ \\
\hline Pasta & $51 \cdot 8$ & 61.5 & +9.7 \\
\hline Whole cereals & $9 \cdot 1$ & 23.2 & +14.2 \\
\hline \multicolumn{4}{|l|}{ Dairy } \\
\hline Cheese & $10 \cdot 0$ & $11 \cdot 2$ & $+1 \cdot 2$ \\
\hline Yoghurt & $9 \cdot 8$ & $14 \cdot 2$ & +4.4 \\
\hline Non-fat milk & $5 \cdot 2$ & $10 \cdot 0$ & $+4 \cdot 8$ \\
\hline Whole milk & $97 \cdot 8$ & $109 \cdot 4$ & +11.6 \\
\hline \multicolumn{4}{|l|}{ Meat } \\
\hline Processed meat & $11 \cdot 3$ & 1.62 & $-9 \cdot 7$ \\
\hline Eggs & $11 \cdot 1$ & $15 \cdot 9$ & +4.8 \\
\hline Chicken & 39.6 & 48.9 & $+9 \cdot 3$ \\
\hline Fish, seafood & 28.9 & 43.9 & $+15 \cdot 0$ \\
\hline Red meat & $80 \cdot 0$ & $67 \cdot 0$ & $-13 \cdot 0$ \\
\hline \multicolumn{4}{|l|}{ Oils } \\
\hline Margarine, butter & $9 \cdot 0$ & 2.04 & -6.96 \\
\hline Olive & 0.0 & $0 \cdot 15$ & $+0 \cdot 1$ \\
\hline \multicolumn{4}{|l|}{ Others } \\
\hline Sugar-sweetened beverages & $121 \cdot 3$ & 31.9 & -89.4 \\
\hline Snacks & $15 \cdot 6$ & 1.7 & $-13 \cdot 9$ \\
\hline Manioc flour & 8.5 & $9 \cdot 6$ & $+1 \cdot 1$ \\
\hline Sweets & $18 \cdot 4$ & $20 \cdot 1$ & $+1 \cdot 7$ \\
\hline
\end{tabular}

Observed diet of Brazilian adults (men and women aged 20 years or more, $n$ 25324) from the first National Dietary Survey 2008-2009. Optimized diet obtained by linear programming, using sixty-eight foods, to achieve the least difference from the observed population mean dietary intake while meeting a set of nutritional goals including a reduction in prevalence of inadequate nutrient intakes to $\leq 20 \%$.

*Optimized - observed, difference (in grams).

maintain a range of bone health outcomes assumes minimal sun exposure because of high imprecision in sunlight exposure due to skin pigmentation, latitude, use of sunscreens, cultural differences in dressing habits, among others $^{(23)}$. It is likely that tropical countries, such as Brazil, need less vitamin D from diet than countries from higher latitudes; but, to date, we cannot detail how much solar exposure by itself fulfils the physiological vitamin D needs ${ }^{(33)}$. In fact, the mean serum 25-hydroxyvitamin D concentration in a sample of Brazilians measured throughout the four seasons was about $50 \mathrm{mmol} / \mathrm{l}$ for adults and elderly men and women. This means that about half of the sample did not present vitamin D deficiency in spite of very high prevalence of $\mathrm{Ca}$ and vitamin $\mathrm{D}$ intake inadequacy (85 and $99 \%$, respectively) ${ }^{(34)}$. In addition, both the Institute of Medicine and WHO reports stated that there is insufficient information to define indicators for vitamin E adequacy ${ }^{(24,33)}$ and they are based mainly on the mean intake observed in the USA and other European countries ${ }^{(33)}$.

Limiting nutrients (i.e. nutrients for which the recommended value is not achievable in an optimized diet) were also found in previous studies using linear programming for both individual and mean diet modelling; such as vitamin E, $\mathrm{K}$ and $\mathrm{Na}$ for the American population ${ }^{(35,36)}$, vitamin $\mathrm{D}, \mathrm{Mg}$, $\mathrm{Na}, \mathrm{Ca}$ and vitamin $\mathrm{E}$ for the French population ${ }^{(6,11)}$, and fibre and vitamin A for the Japanese population ${ }^{(8)}$. As pointed out in the last study ${ }^{(8)}$, these differences in limiting nutrients found in various countries might be explained by the differences in both dietary patterns and dietary recommendations adopted. In the present study, unlike the others, we did not use the EAR value as a nutrition target. Instead, we derived the target that should be reached in the optimized diet in a way that at least $80 \%$ of the population would have an intake higher than the EAR. Moreover, we did not use the Adequate Intake as a target for nutrients with no EAR established because it consists of a set of intake recommendations in which there is not enough information to define a mean requirement, being derived from mean intake in healthy American and Canadian populations, which could be even lower than the actual unknown need ${ }^{(26)}$.

The feasibility of such changes in the optimized diet may be a point of debate. In fact, participation of beans in the Brazilian household food basket has decreased throughout the last three decades ${ }^{(20,21)}$. Price of and access to fruits and vegetables may act as a barrier to encourage their consumption especially for low-income families ${ }^{(18)}$. However, the acceptability constraints imposed to our model were more restrictive than the ones used in other studies that modelled population mean $\operatorname{diet}^{(8,14)}$. Such acceptability constraints were obtained from mean sample strata intakes, which represent actual mean intakes in delimited sectors with geographical and socio-economic homogeneity. This makes the distribution of mean intakes more heterogeneous, and this is the reason we opted for such restrictive constraints. From our point of view, more flexible percentiles such as the 90th or 95th would result in a very non-realistic or unaffordable diet.

Some limitations, however, should be addressed. First, there is no set of nutrient recommendations derived specifically for the Brazilian population and the Dietary Reference Intakes adopted here were established for the US population, which implies that the requirements taken into account (among other factors) are the mean weight and height, and food pattern and diversity; the latter is related to nutrient bioavailability. Second, the Brazilian food composition data set does not comprise a food and nutrient list sufficient to be used in national surveys; thus we calculated nutrient contents using the US Department of Agriculture food composition using the Nutrition Data System for Research (NDS-R) program, version $2008^{(37)}$. Nevertheless, both the Dietary Reference Intakes and the US Department of Agriculture food composition have been used to estimate nutrient intakes and prevalence of inadequacy in the Brazilian population ${ }^{(3,4)}$, which put both observed and optimized diets under the same uncertainties. Third, to estimate the prevalence of nutrient inadequacy, we assumed the intake variability in the optimized diet to be the same as in the observed diet, which is 
consistent with a scenario where everyone modifies their intake by the same level. Finally, the optimal solution lies in the assumptions underlying diet modelling. For example, the choice of the target for the nutrient adequacy and the acceptability constraints were arbitrary. However, we did not consider other targets for adequacy because the prevalence of inadequacy, in most of the cases, was either too high or low; thus higher targets (e.g. 30\%) or lower (e.g. $10 \%$ ) would not affect this figure, especially for those highly inadequate nutrients. Sensitivity analysis can be performed to check some of the model assumptions, and it provides the extension of the objective values and the variable values (optimized food quantities) changes while the nutrient composition or other constraints change. It also provides information on the relative importance of a given food or nutrient in the solution by assessing the robustness of the model after removing any/some food(s) or constraint(s) ${ }^{(38)}$.

\section{Conclusion}

In conclusion, the present study showed that changes in the current diet, respecting constraints of acceptability, increased nutrient intakes and placed the population at lower risk of nutrient inadequacies. However, to meet nutritional adequacy for all nutrients would require major dietary changes. Given all the uncertainties, such as food composition, measurement error in dietary reporting and nutrient bioavailability, these amounts in the optimized diet should not be seen as rigorous food intake targets. Instead, it gives us a picture of which components of the diet should be focused upon in interventions or programmes to promote healthy food patterns.

\section{Acknowledgements}

Financial support: This research received no specific grant from any funding agency in the public, commercial or not-for-profit sectors. S.Q. was financed ( $\mathrm{PhD}$ fellowship) by Coordenação de Aperfeiçoamento de Pessoal de Nível Superior (CAPES). CAPES had no role in the design, analysis or writing of this article. Conflict of interest: The authors declare no confiicts of interest. Authorship: S.Q. and E.V.-J. performed the statistical analyses, interpreted the data and wrote the paper; R.S., N.D. and M.M. performed the interpretation of the data and wrote the paper. All authors actively participated in the manuscript preparation, and they all read and approved the final version of the manuscript. Ethics of human subject participation: Not applicable.

\section{References}

1. Roman Viñas B, Ribas Barba L, Ngo J et al. (2011) Projected prevalence of inadequate nutrient intakes in Europe. Ann Nutr Metab 59, 84-95.

2. Moshfegh A, Goldman J \& Cleveland L (2005) What We Eat in America. NHANES 2001-2002: Usual Nutrient Intakes from Food Compared to Dietary Reference Intakes. Washington, DC: US Department of Agriculture, Agricultural Research Service.

3. Araujo MC, Bezerra IN, Barbosa FdS et al. (2013) Consumo de macronutrientes e ingestão inadequada de micronutrientes em adultos. Rev Saude Publica 47, Suppl. 1, 177S-189S.

4. Fisberg RM, Marchioni DML, Castro MAd et al. (2013) Ingestão inadequada de nutrientes na população de idosos do Brasil: Inquérito Nacional de Alimentação 2008-2009. Rev Saude Publica 47, Suppl. 1, 222S-230S.

5. Hlaing LM, Fahmida U, Htet MK et al. (2015) Local food-based complementary feeding recommendations developed by the linear programming approach to improve the intake of problem nutrients among 12-23month-old Myanmar children. Br J Nutr 116, Suppl. 1, S16-S26.

6. Maillot M, Vieux F, Amiot MJ et al. (2010) Individual diet modeling translates nutrient recommendations into realistic and individual-specific food choices. Am J Clin Nutr 91, 421-430.

7. Darmon N, Ferguson E \& Briend A (2002) Linear and nonlinear programming to optimize the nutrient density of a population's diet: an example based on diets of preschool children in rural Malawi. Am J Clin Nutr $\mathbf{7 5}$, $245-253$.

8. Okubo H, Sasaki S, Murakami K et al. (2015) Designing optimal food intake patterns to achieve nutritional goals for Japanese adults through the use of linear programming optimization models. Nutr J 14, 57.

9. Ferguson EL, Darmon N, Fahmida U et al. (2006) Design of optimal food-based complementary feeding recommendations and identification of key 'problem nutrients' using goal programming. J Nutr 136, 2399-2404.

10. Darmon N, Ferguson EL \& Briend A (2006) Impact of a cost constraint on nutritionally adequate food choices for French women: an analysis by linear programming. J Nutr Educ Behav 38, 82-90.

11. Maillot M, Darmon N \& Drewnowski A (2010) Are the lowest-cost healthful food plans culturally and socially acceptable? Public Health Nutr 13, 1178-1185.

12. Perignon M, Masset G, Ferrari G et al. (2016) How low can dietary greenhouse gas emissions be reduced without impairing nutritional adequacy, affordability and acceptability of the diet? A modelling study to guide sustainable food choices. Public Health Nutr 19, 2662-2674.

13. Cleveland LE, Escobar AJ, Lutz SM et al. (1993) Method for identifying differences between existing food intake patterns and patterns that meet nutrition recommendations. J Am Diet Assoc 93, 556-563.

14. Barré T, Vieux F, Perignon M et al. (2016) Reaching nutritional adequacy does not necessarily increase exposure to food contaminants: evidence from a whole-diet modeling approach. J Nutr 146, 2149-2157.

15. Instituto Brasileiro de Geografia e Estatística (2011) Análise do Consumo Alimentar Pessoal no Brasil, 2008-2009 (Family Budget Survey, 2008-2009). Rio de Janeiro: IBGE.

16. Barbosa FS, Brito FSB \& Junger W (2013) Assessing usual dietary intake in complex sample design surveys. Rev Saude Publica 47, Suppl. 1, S171-S176.

17. Briend A, Darmon N, Ferguson E et al. (2003) Linear programming: a mathematical tool for analyzing and optimizing children's diets during the complementary feeding period. J Pediatr Gastroenterol Nutr 36, 12-22.

18. Darmon N, Ferguson EL \& Briend A (2002) A cost constraint alone has adverse effects on food selection and nutrient density: an analysis of human diets by linear programming. J Nutr 132, 3764-3771.

19. Instituto Brasileiro de Geografia e Estatística (2011) Tabela de Composição Nutricional dos Alimentos Consumidos no Brasil. Rio de Janeiro: IBGE. 
20. Levy-Costa RB, Sichieri R, Pontes NS et al. (2005) Household food availability in Brazil: distribution and trends (19742003). Rev Saude Publica 39, 530-540.

21. Levy RB, Claro RM, Mondini L et al. (2012) Distribución regional y socioeconómica de la disponibilidad domiciliaria de alimentos en Brasil, 2008-2009. Rev Saude Publica 46, 6-15.

22. Beaton GH, Milner J, Corey P et al. (1979) Sources of variance in 24-hour dietary recall data: implications for nutrition study design and interpretation. Am J Clin Nutr 32, 2546-2559.

23. Institute of Medicine (2011) Dietary Reference Intakes for Calcium and Vitamin. D. Washington, DC: National Academies Press.

24. Institute of Medicine (2000) Dietary Reference Intakes for Vitamin C, Vitamin E, Selenium, and Carotenoids. Washington, DC: National Academies Press.

25. Institute of Medicine (2006) Dietary Reference Intakes: The Essential Guide to Nutrient Requirements. Washington, DC: National Academies Press.

26. Institute of Medicine (2000) Dietary Reference Intakes: Applications in Dietary Assessment. Washington, DC: National Academies Press.

27. Carriquiry AL (1999) Assessing the prevalence of nutrient inadequacy. Public Health Nutr 2, 23-33.

28. Tooze JA, Midthune D, Dodd KW et al. (2006) A new statistical method for estimating the usual intake of episodically consumed foods with application to their distribution. J Am Diet Assoc 106, 1575-1587.

29. Nilson EAF, Jaime PC \& Resende DdO (2012) Iniciativas desenvolvidas no Brasil para a redução do teor de sódio em alimentos processados. Rev Panam Salud Publica 32, 287-292.

30. World Cancer Research Fund (2007) Food, Nutrition, Physical Activity, and the Prevention of Cancer: A Global Perspective. Washington, DC: AICR.
31. Souza AdM, Pereira RA, Yokoo EM et al. (2013) Alimentos mais consumidos no Brasil: Inquérito Nacional de Alimentação 2008-2009. Rev Saude Publica 47, Suppl. 1, 190S-199S.

32. Wilson N, Nghiem N, Ni Mhurchu C et al. (2013) Foods and dietary patterns that are healthy, low-cost, and environmentally sustainable: a case study of optimization modeling for New Zealand. PLoS One 8, e59648.

33. Food and Agriculture Organization of the United Nations \& World Health Organization (2002) Vitamin and Mineral Requirements in Human Nutrition. Joint FAO/WHO Expert Consultation. Geneva: WHO.

34. Martini LA, Verly E Jr, Marchioni DML et al. (2013) Prevalence and correlates of calcium and vitamin D status adequacy in adolescents, adults, and elderly from the health survey - São Paulo. Nutrition 29, 845-850.

35. Masset G, Monsivais P, Maillot M et al. (2009) Diet optimization methods can help translate dietary guidelines into a cancer prevention food plan. J Nutr 139, 1541-1548.

36. Gao X, Wilde PE, Lichtenstein AH et al. (2006) The 2005 USDA Food Guide Pyramid is associated with more adequate nutrient intakes within energy constraints than the 1992 Pyramid. J Nutr 136, 1341-1346.

37. University of Minnesota, Nutrition Coordinating Center (2003) University of Minnesota Nutrition Data System for Research - NDSR. http://www.ncc.umn.edu/ndsr-databasepage/ (accessed February 2017).

38. Buttriss JL, Briend A, Darmon N et al. (2014) Diet modelling: how it can inform the development of dietary recommendations and public health policy. Nutr Bull 39, 115-125.

39. World Health Organization (2003) Diet, Nutrition and the Prevention of Chronic Diseases. Report of a Joint WHO/FAO Expert Consultation. WHO Technical Report Series no. 916. Geneva: WHO. 